\title{
PCDD/Fs and PCBs in Soils: a Study of Case in the City of Belo Horizonte-MG
}

\author{
Igor C. Pussente, ${ }^{*, a}$ Guillaume ten Dam, ${ }^{b}$ Stefan van Leeuwen ${ }^{b}$ and Rodinei Augusti ${ }^{a}$ \\ ${ }^{a}$ Universidade Federal de Minas Gerais, UFMG, Av. Antônio Carlos, 6627, \\ 31270-901 Belo Horizonte-MG, Brazil \\ ${ }^{b}$ Rikilt, Institute of Food Safety, Wageningen UR, The Netherlands
}

\begin{abstract}
Dioxins (polychlorinated dibenzo- $p$-dioxins and polychlorinated dibenzofurans ( $\mathrm{PCDD} / \mathrm{Fs}$ ) and polychlorinated biphenyls (PCBs)) are substances that represent a global concern due to their ubiquitous presence and toxicity. Industrial processes and other human activities as well as uncontrollable accidents are the main sources that release these pollutants into the environment. The presence of these compounds has been reported in soils from Europe, Asia and Africa, but currently, there is not much information of dioxin levels in soils from Brazil. This paper presents the levels of PCDD/Fs, dioxin-like PCBs (dl-PCBs) and non-dioxin-like PCBs (ndl-PCBs) in soils collected from urban areas of Belo Horizonte city, Minas Gerais State, Brazil. Total toxic equivalents (TEQ) observed ranged from 0.43 to $4.54 \mathrm{ng} \mathrm{TEQ} \mathrm{kg}^{-1} \mathrm{~d} . \mathrm{m}$. The highest concentration TEQ found was $2.68( \pm 1.63) \mathrm{ng}$ TEQ $\mathrm{kg}^{-1} \mathrm{~d} . \mathrm{m}$. The low total TEQ achieved suggests that the locations evaluated are not being affected by possible sources of dioxin emissions, although Belo Horizonte is surrounded by a number of them.
\end{abstract}

Keywords: PCDD/Fs, dioxin-like PCBs, urban soil, distribution pattern

\section{Introduction}

"Dioxins" is a group of environmental contaminants that are present in almost all compartments of the world. ${ }^{1,2}$ They have been subject of concern for governments and the World Health Organization (WHO), since they are toxic at trace levels and extremely stable. ${ }^{3}$ Typically the name dioxins refers to polychlorinated dibenzo- $p$-dioxins (PCDDs) and polychlorinated dibenzofurans (PCDFs). The congeners with chlorine atoms at the 2, 3, 7 and 8 positions of the aromatic rings are the most toxic. ${ }^{4}$ In addition, a number of polychlorinated biphenyls (PCBs), known as dioxin-like PCBs (dl-PCBs), shows similar behavior as these 2, 3, 7, 8 substituted dioxins ${ }^{3}$ and are also included in many studies. Other 6 PCBs, known as non-dioxin-like PCBs (ndl-PCBs), are also of interest due to their high occurrence. ${ }^{5}$ All of these compounds have been included in the Stockholm Convention on persistent organic pollutants (POPs) ${ }^{2}$ and have been studied extensively in developed countries. PCDDs and PCDFs are unintentionally industrial products from anthropogenic sources. Once PCDD/Fs are emitted into the atmosphere, they tend to aggregate to solid particulate followed by atmospheric deposition until they

*e-mail: igorquimica@gmail.com reach soils and sediments. Therefore, soils and sediments are regarded as 'reservoirs' of PCDD/Fs, from where they can gradually be released or transferred to other media. ${ }^{6}$ For PCDD/Fs, combustion processes (e.g., waste incinerators, thermal industrial processes and household fires) are believed to be the most significant source of environmental contamination. ${ }^{7,8}$ Other potential sources are industrial processes involving chemical and petrochemical plants, iron and steel production, cement kilns, secondary copper smelters, paper and pulp industries, that contribute to release these compounds into the environment. ${ }^{9,10}$ Congeners of PCBs are generally more ubiquitous than those of PCDD/Fs due their commercial application during several decades in the last century. ${ }^{5}$ Most PCBs were commercially produced in the United States as standard mixtures bearing the brand name Aroclor. ${ }^{11}$ Different Aroclor mixtures were used at different times and for diverse applications (e.g., heat transfer fluids, hydraulic lubricants, flame retardants, plasticizers, and as dielectric fluids in electronic components such as capacitors and transformers). In electrical equipment manufacturing in the United States, Aroclor 1260 and 1254 were the main mixtures used before 1950s. Afterwards, during the 1950s and 1960s, Aroclor 1242 was the main mixture used until it was phased out in 1971 and replaced by Aroclor 1016. ${ }^{12}$ 
Although environmental contamination by PCBs is mostly a result of several PCB products, spot contamination might be traced back to a specific industry or application. ${ }^{13}$ Emissions of dioxins generally do not contain a homogeneous mixture of congeners since the individual levels depend mostly on the process, the materials used in the process, products involved as well as environmental and biological transfer rates. In addition, the measured total levels can vary significantly depending on the season and weather, e.g., in winter PCDD/PCDF concentrations in air may be higher by a factor of ten on toxic equivalents (TEQ) basis than in summer, levels in grass are generally higher in winter than in other seasons and levels in dry soil are generally higher than in wet soils. ${ }^{6,14}$

At several locations in the world, soil has been investigated for the presence of particular dioxins. A number of countries have established guidelines concerning maximum limits of dioxin concentration in soils, focused on the control of dioxins in stack emissions, with the objective of reducing human exposure and protecting human health. Sweden considers $10 \mathrm{ng}$ I-TEQ kg-1 d.m. (d.m. = dry matter) the maximum limit for soil in residential area, while Germany and the Netherlands establish $1000 \mathrm{ng}$ I-TEQ kg-1 d.m. For Brazil, no maximum limits for soils have been established. ${ }^{6}$ Available data on concentrations of PCDD/Fs in the environment (air, soil, water or sediments), animals, food and even in the human body, or levels of emissions from possible sources of unintentional formation, are scarce in Brazil. ${ }^{15}$ Moreover, United Nations Environment Programme (UNEP) has published data on concentrations of PCDD/Fs in soils of assorted locations in Brazil. The range levels reported were between 0.03-900 ng I-TEQ $\mathrm{kg}^{-1}{ }^{16}$

Belo Horizonte city is the capital of Minas Gerais (MG) state, located in the southeast of Brazil, with $331 \mathrm{~km}^{2}$ and with an estimated population of approximately 2.5 million in the urban area. Including neighbor municipalities, the population in its metropolitan area reaches 5.7 million habitants. The region has become attractive to industrial sectors after an industrial district has been created in 1941 . Construction, high technology, and other industries make it one of the most economically dynamic urban areas in Brazil. ${ }^{17}$ Due to its geographical location that reduces the cost of transportation of raw materials and flow of products, important industries of different sectors, such as mining, automobiles, steel products, textile, cosmetic, food, chemicals, pharmaceuticals, furnishing and petroleum refinery have installed their plants in the industrial district. ${ }^{18}$

The objective of this study is to provide an initial investigation about the levels of 17 congeners of PCDD/Fs, 12 dl-PCBs, which are comprised by the non-ortho PCBs (NO-PCBs) and mono-ortho PCBs (MO-PCBs), and
6 ndl-PCBs in soils collected in the urban area of Belo Horizonte-MG, Brazil. Additional information about the sampling areas was used to assess differences among groups and distribution profiles of the compounds studied. The present data were compared with levels in soils from other cities in Brazil and several countries over the world.

\section{Experimental}

\section{Sampling}

Three individual samples were taken from six places in the urban area of Belo Horizonte including the city center, residential areas (BV, CS, PC, AL and PR), and one sample (DQ) at the Department of Chemistry of Federal University of Minas Gerais (UFMG). The spatial distribution of the sampled sites is shown in Figure $1 .{ }^{19}$ Samples were taken from the top layer of the soil, the material was collected in a glass flask and stored at room temperature upon transportation for analysis at the RIKILT LaboratoryWageningen UR, in The Netherlands.

\section{Analysis}

Samples were analyzed for PCDD/Fs and PCBs by gas chromatography coupled to high-resolution mass spectrometry (GC-HRMS) using methods previously developed and validated. ${ }^{20,21}$ All standards were purchased from Cambridge Isotope Laboratories (Tewksbury, MA, USA) and are listed in Table S1 (Supplementary Information section). All solvents used ( $n$-hexane, dichloromethane, ethylacetate and toluene) were purchased from Actu-All Chemicals (Randmeer, The Netherlands) and were of PEC grade. The samples were dried in a stove at $60{ }^{\circ} \mathrm{C}$ for $72 \mathrm{~h}$ and homogenized. Each sample collected was weighed (roughly $5 \mathrm{~g}$ ) and transferred to glass beakers. Diatomaceous earth (approximately $5 \mathrm{~g}$ ) was added to each beaker and the mixtures homogenized with a glass-stirring rod. After the addition of the internal standards, $50 \mathrm{pg}$ of ${ }^{13} \mathrm{C}$-labeled PCDDs, PCDFs and NO-PCBs and $1000 \mathrm{pg}$ of ${ }^{13} \mathrm{C}$-labeled MO-PCBs and ndl-PCBs (see Table S1) to each beaker, the mixtures were further homogenized. These mixtures were then transferred to an accelerated solvent extraction (ASE) tube, which was then inserted into the ASE instrument (Thermo Fisher Dionex, Sunnyvale, USA) for extraction with toluene:ethanol (9:1, v/v) at $150{ }^{\circ} \mathrm{C}$ and 1500 psi. The resulting extracts, with approximately a final volume of $150 \mathrm{~mL}$, were filtered over a funnel with anhydrous $\mathrm{Na}_{2} \mathrm{SO}_{4}$ and the solvent evaporated to dryness in a rotary evaporator. The residues were recovered with $n$-hexane 


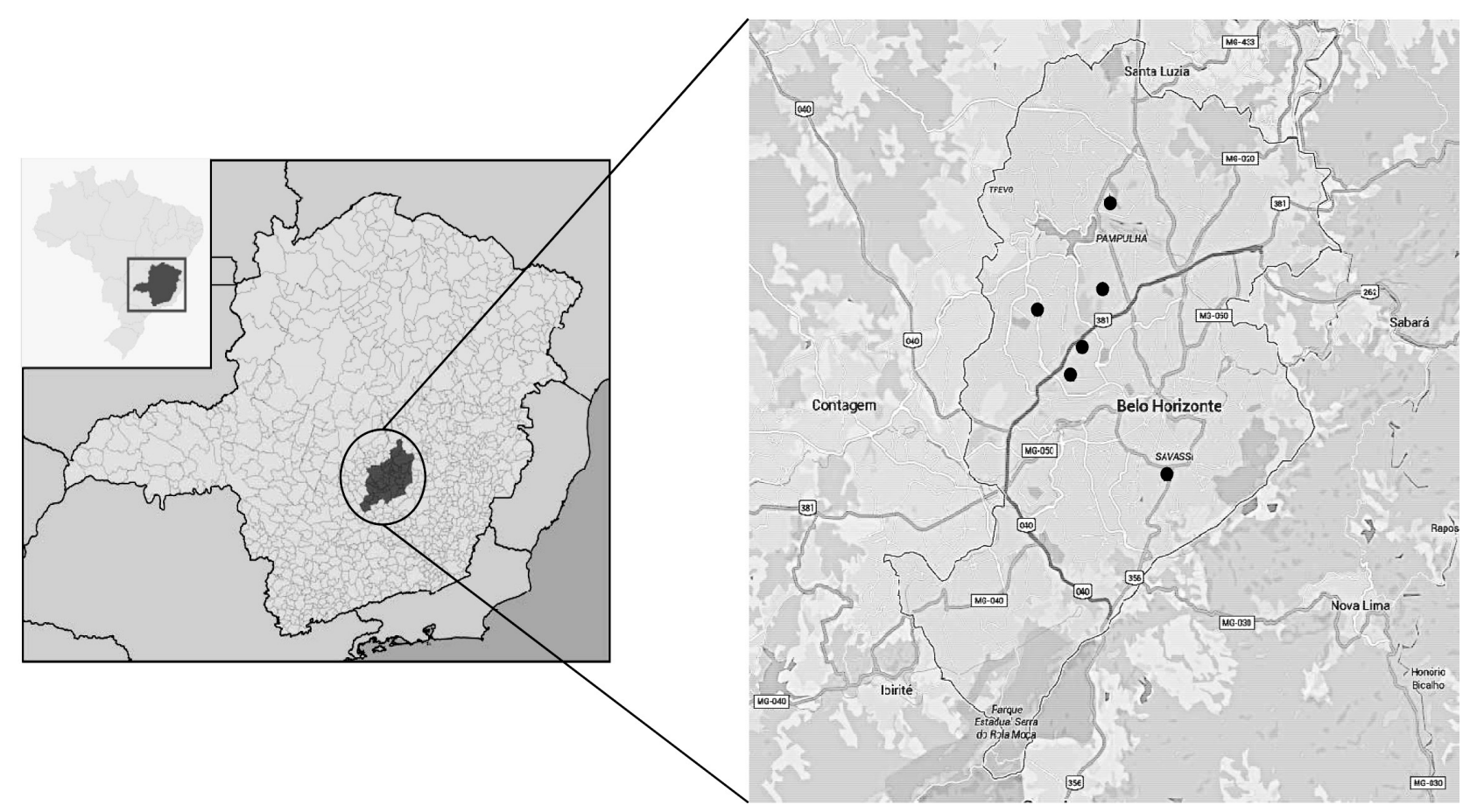

Figure 1. Map of Minas Gerais state and Belo Horizonte city, Brazil, showing the locations where the samples were collected.

and transferred to a graduated cylinder. After addition of $n$-hexane (approximately $25 \mathrm{~mL}$ ) and $100 \mathrm{pg}$ of the clean-up standard $\left({ }^{37} \mathrm{Cl}_{4}\right.$-2,3,7,8-tetra chlorinated dioxin (TCDD), see Table S1), the samples were submitted to the clean-up procedure, for which an automated system (PowerPrep ${ }^{\mathrm{TM}}$ FMS Inc., Waltham, MA, USA) was used. This system works with the following chromatographic columns: acid silica, neutral silica, basic alumina and activated carbon/Celite, all of them purchased directly from the manufacturer. ${ }^{22}$

For elution through the columns the following solvents and mixtures were used: $n$-hexane, $n$-hexane/ dichloromethane $(1: 1 \mathrm{v} / \mathrm{v})$, ethyl acetate/toluene $(1: 1 \mathrm{v} / \mathrm{v})$ and toluene. In the 24 automated steps (described in Table S2, Supplementary Information section), the samples were cleaned and the MO-PCBs and ndl-PCBs were collected in fraction A (eluted with $120 \mathrm{~mL}$ of dichloromethane/ $n$-hexane), whereas PCDDs, PCDFs and NO-PCBs were collected in fraction B (eluted with $75 \mathrm{~mL}$ of toluene). Both fractions were evaporated to a final volume of $500 \mu \mathrm{L}$. Recovery standards (see Table S1) were added in fractions A (250 pg of ${ }^{13} \mathrm{C}-1,2,3,4$-TCDD in isooctane) and $\mathrm{B}\left(100 \mathrm{pg}\right.$ of ${ }^{13} \mathrm{C}-1,2,3,4-\mathrm{TCDD}$ and $100 \mathrm{pg}$ of ${ }^{13} \mathrm{C}-2,3,4,6,7,8$-hexa chlorinated furan (HxCDF) in toluene). In fractions $\mathrm{A}$ and $\mathrm{B}, 2 \mathrm{~mL}$ of iso-octane and toluene were added to wash the flasks, respectively. The final solutions were again evaporated to a final volume of $500 \mu \mathrm{L}$.

The fractions were analyzed on a GC/HRMS instrument (GC: Agilent HP6890+GC, HRMS: Autospec, Ultima system, Waters, Manchester, UK) for PCDD/Fs, dl-PCBs and ndl-PCBs. The instrument tuning met the minimum required resolving power of 10.000 (10\% valley).

For the PCDD/Fs and NO-PCBs, $100 \mu \mathrm{L}$ was injected on a programmed temperature vaporizer (Gerstel, Mülheim an der Ruhr, Germany) in the solvent vent mode while $2 \mu \mathrm{L}$ was injected in the splitless mode for the MO-PCBs and ndl-PCBs fraction. Separation was performed on a DB-5MS fused silica capillary column $(60 \mathrm{~m} \times 0.25 \mathrm{~mm} \times 0.25 \mu \mathrm{m})$ from Agilent J\&W (Folson, USA) using helium (purity 6.0) as the carrier gas with a constant column flow of $1.2 \mathrm{~mL} \mathrm{~min}^{-1}$. Limits of quantification (LOQ) were based on signal/noise ratios $(\mathrm{S} / \mathrm{N})$ and were approximately 0.02 , 0.05 and $5.00 \mathrm{ng} \mathrm{kg}^{-1} \mathrm{~d}$.m. for PCDD/Fs, NO-PCBs and MO-PCBs, respectively, and $0.05 \mu \mathrm{g} \mathrm{kg}^{-1} \mathrm{~d}$.m. for ndlPCBs. LOQs were corrected by recovery and sample intake for each compound in every sample.

The identification of individual PCDD/Fs, dl-PCBs (NO-PCBs and MO-PCBs) and ndl-PCBs was performed on the basis of the retention times (matching that of the corresponding standard compound), the signal-to-noise ratio (higher than 3:1) and the isotopic ratio between the quantitation and confirmation ions (within $\pm 15 \%$ of the theoretical value). Table S3 (Supplementary Information section) displays the exact masses with the ion ratios for each PCDD/F and PCB evaluated herein. The calibration curves were built for quantification purposes by using the internal standard methodology. Labeled compounds $\left({ }^{13} \mathrm{C}\right)$ were used as internal standards. The following 
concentrations of each individual congener were employed to build the calibration curves: PCDD/Fs $(0.002 ; 0.005$;

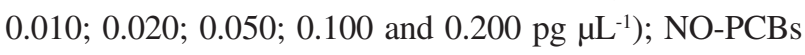
$(0.002 ; 0.005 ; 0.010 ; 0.020 ; 0.050 ; 0.100,0.200,1.000$ and $\left.2.000 \mathrm{pg} \mu \mathrm{L}^{-1}\right)$; MO-PCBs and ndl-PCBs (0.100; 0.250; $0.500 ; 1.000 ; 2.500 ; 5.000 ; 10.00 ; 50.00$ and $\left.100.0 \mathrm{pg}_{\mu} \mathrm{L}^{-1}\right)$. The linearity expressed as the coefficient of determination $\left(r^{2}\right)$ varied from $0.9976<r^{2}<0.9999$ for the PCDD/Fs, dl-PCBs and ndl-PCBs, as indicated in Table S3. To determine the amount of PCDD/Fs, dl-PCBs and ndl-PCBs, the areas of the sample peaks are compared with those of the known amount of the corresponding peaks of the compounds in the calibration standard solutions, based on the principle of isotope dilution. The response of each compound relative to its labeled analogue is determined using both the primary and secondary exact $\mathrm{m} / \mathrm{z}$ values, for each calibration standard. ${ }^{23}$

For native and labeled compound in the calibration curves, the relative response factor (RRF) and its average was calculated using equations 1 and 2, respectively:

$\mathrm{RRF}_{(\mathrm{IS})}=\frac{\mathrm{A}_{\mathrm{IS}} \times \mathrm{Q}_{\mathrm{RS}}}{\mathrm{Q}_{\mathrm{IS}} \times \mathrm{A}_{\mathrm{RS}}}$

where $\mathrm{A}_{\mathrm{IS}}$ is the response (one of the two $\mathrm{m} / \mathrm{z}$ values) of a given internal standard; $A_{R S}$ is the response (one of the two $\mathrm{m} / \mathrm{z}$ values) of a given recovery standard; $\mathrm{Q}_{\mathrm{IS}}$ is the amount of a given internal standard $\mathrm{pg} \mu \mathrm{L}^{-1} ; \mathrm{Q}_{\mathrm{RS}}$ is the amount of a given recovery standard $\mathrm{pg} \mu \mathrm{L}^{-1}$.

$\overline{\mathrm{RRF}_{(\mathrm{n})}}=\frac{1}{\mathrm{~m}} \times \sum_{\mathrm{i}=1}^{\mathrm{m}} \mathrm{RRF}_{\mathrm{i}}(\mathrm{n})$

where $\mathrm{m}$ is the number of standards (concentration levels); $\mathrm{n}$ is the native component; $\mathrm{i}$ is the calibration level. Consequently the content of each component is calculated using equation 3 :

$\mathrm{C}_{\mathrm{x}}=\frac{\mathrm{A}_{\mathrm{x}} \times \mathrm{Q}_{\mathrm{is}}}{\mathrm{A}_{\mathrm{is}} \times \mathrm{DIV} \times \overline{\mathrm{RRF}_{(\mathrm{n})}}}$

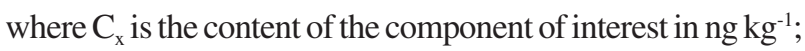
$\mathrm{A}_{\mathrm{x}}$ is the response (one of the two $\mathrm{m} / \mathrm{z}$, values) of a given native compound in the sample extracts; $A_{I S}$ is the response (one of the two $\mathrm{m} / \mathrm{z}$, values) of a given labeled internal standard in sample extracts; $Q_{\text {IS }}$ is the amount of injected labeled internal standard pg $\mu^{-1}$; DIV is the calculation factor from concentration (pg $\mu \mathrm{L}^{-1}$ ) to content on sample basis $\left(\mathrm{ng} \mathrm{kg}^{-1}\right)$. The calculated concentrations of PCDD/Fs, dl-PCBs and ndl-PCBs were recalculated to TEQ values. The TEQ values are calculated by multiplying the TEF value (Table 1$)^{3}$ of each compound by its true concentration.

\section{Quality assurance and quality control}

In the batch of the soil samples it was included one blank sample (consisting of diatomaceous earth) spiked with native and ${ }^{13} \mathrm{C}$-labelled compounds of each congener of PCDD/Fs and PCBs to assure the attainment of accurate data and also for analyses control. Diatomaceous earth was chosen as a convenient blank due to the impossibility to find a true soil blank. Diatomaceous earth has similar consistency than the soil samples and is mixed to them previously to the extraction procedure. The concentrations of PCDD/Fs and PCBs in the diatomaceous earth were below their LOQs (Table 1). The results for PCDD/Fs, $\mathrm{dl}-\mathrm{PCBs}$ and ndl-PCBs in the spiked diatomaceous earth were also included in Table 1 and are within the expected values. The recoveries for the native compounds in the blank spiked sample and ${ }^{13} \mathrm{C}$-labelled PCDD/Fs and PCBs in soil spiked samples are presented in Table S4 (Supplementary Information section). The recoveries are in the ranges of 80-114, 80-111 and 82-115\%, respectively (Table S4). The recovery results are within the permitted range, from 80 to $120 \%$, for confirmatory methods according to the European regulation 2012/252/EU. ${ }^{24}$ As can be visualized in Table S4, the results were consistent and ensured the attainment of accurate data for all analyzed samples. The method used for the analyses of PCDD/Fs and PCBs is very steady and was fully validated following the restrict quality control criteria of analyses for PCDD/Fs and PCBs of the RIKILT Institute. Moreover, the method performance has been successfully verified by the proficiency testing (PT) organized by the European Union Reference Laboratory for Dioxins and PCBs in Feed and Food (Freiburg, Germany).

\section{Results and Discussion}

\section{PCDD and PCDFs}

Eighteen samples from the top layer of soils were taken in six locations of Belo Horizonte-MG, five of them in residential areas (BV, CS, PC, AL and PR) and one collected at the campus of Federal University of Minas Gerais (DQ). The results of the individual congeners are reported in Table 1. The total TEQ levels observed ranged from 0.43 to $4.54 \mathrm{ng}$ TEQ $\mathrm{kg}^{-1} \mathrm{~d}$.m. with an average result of $1.56( \pm 1.03) \mathrm{ng}$ TEQ $\mathrm{kg}^{-1} \mathrm{~d} . \mathrm{m}$. The highest level of dioxins-TEQ was in the area PR followed by PC, DQ, $\mathrm{AL}, \mathrm{CS}$ and BV. Concerning the contribution to the dioxin-TEQ, congeners of PCDD ranged from 42 to $90 \%$, while PCDF from 10 to $58 \%$. The location PR showed the highest contribution of PCDD with an average of $82 \%$, while the lowest contribution of PCDD was found in the 
CS location (51\%). The pattern of congeners contributions consisted mostly of octa chlorinated dioxin (OCDD, range: 61-95\%), hepta chlorinated dioxin (HpCDD, 4-19\%), octa chlorinated furan (OCDF, range: $0.3-12 \%$ ) and hepta chlorinated furan (HpCDF, range: $0.2-10 \%)$. Clearly OCDD was the most abundant compound in all soil samples. The relatively high OCDD concentration shows good agreement to what had been found in other studies for soils. For instance, Brzuzy and Hites ${ }^{7}$ found high contributions of OCDD in soil samples from Virginia, USA ( $91 \%$ of PCDD/F), Indiana, USA (about $96 \%$ of PCDD/F), ${ }^{25}$ and in South Africa (84\% of PCDD/F). ${ }^{26}$ Hites ${ }^{26}$ in a study comparing the distribution of PCDD/Fs in soil and combustion sources, observed that the less chlorinated compounds (i.e., tetra- and penta-) are found to a greater extent in the vapor phase. Once air mass moves away from the urban sources, the dioxins are diluted with cleaner air and a small portion of the tetraand penta- $(<40 \%)$ congeners are deposited in the soil, preferably near the emission source. Also according to Hites, ${ }^{26}$ the more chlorinated PCDD/Fs (i.e., hexa to octa), have a greater tendency to be removed from atmosphere when the compounds are bound to particles. Later et al. ${ }^{10}$ suggested that when PCDFs are predominant the potential emission source is near the spot contaminated. On the other hand, the profiles with PCDDs predominant are classified as "sink", suggesting that the studied area is distant from a possible source of emission. Additionally, Domingo et al. ${ }^{27}$ showed that higher chlorinated congeners are much easier to be settled on the soil than lower chlorinated ones. Therefore the patterns of PCDD/Fs in urban soil from Belo Horizonte are congruent with patterns described for different countries over the world.

\section{PCBs}

The range of values for dl-PCBs was 0.04-0.93 ng TEQ $\mathrm{kg}^{-1} \mathrm{~d}$.m. and for ndl-PCBs was 0.22-7.48 $\mathrm{ng} \mathrm{g}^{-1} \mathrm{~d}$.m. (Table 1). The contribution of dl-PCBs in the total TEQ were $2-52 \%$ and in only one sample (DQ-1) the level of dl-PCBs was predominant in relation to $\mathrm{PCDD} / \mathrm{Fs}$.

\section{Potential sources}

In Figure 2 it was represented all TEQ values for PCDD/Fs, dl-PCBs and ndl-PCBs per sample collected.

$B V$ was considered the cleanest area for dioxins, furans and PCBs, with average levels of $0.55 \mathrm{ng}$ TEQ $\mathrm{kg}^{-1}$ d.m. $( \pm 0.11)$, and for ndl-PCBs was $0.24 \mu \mathrm{g} \mathrm{kg}{ }^{-1}$ d.m. $( \pm 0.02)$. Second lower levels were from the CS area with 0.72 ng TEQ kg ${ }^{-1}$ d.m. ( \pm 0.15$)$. Cement kilns plant located in the city of Pedro Leopoldo, $25 \mathrm{~km}$ north from BV and CS area, could influence both areas. In general they are known to emit PCDD/Fs, but estimates of the amounts and patterns of these emissions vary widely. ${ }^{28}$ Generally, the transport and deposition of PCDD/Fs depend on the atmospheric phenomena and the distances from the source. ${ }^{25}$ The low levels observed suggest that the BV and CS areas are not affected significantly by surrounding potential sources of emission. However, a complementary study is required to assess the environmental impact of these kilns in terms of PCDD/Fs levels released to atmosphere.

In contrast, somewhat higher levels were found in samples from the south of Belo Horizonte, PR area, the nearest area from the city center. In this location top layers of soil were sampled from individual gardens, approximately $2 \mathrm{~m}^{2}$ each, in a small public square. Levels found in PR-1, PR-2 and PR-3 were 1.53, 1.96 and 4.54 ng TEQ $\mathrm{kg}^{-1}$ d.m., respectively, with PCDDs contributing to TEQ between 73-90\%, while PCDFs ranged 10-27\%. Belo Horizonte is a metropolitan city with high population density and surrounded by industrial and mining activities. One of these industrial districts is situated in Contagem city (approximately $10 \mathrm{~km}$ west from $\mathrm{PR}, \mathrm{AL}$ and $\mathrm{PC}$ areas) and is supposed to be a potential source of PCDD/Fs. None of the areas nearest to the industrial district showed high levels of these compounds. As mentioned before, the behavior of these compounds emitted to atmosphere will be influenced by natural phenomena. Furthermore, the industrial district should be studied in detail to assess whether there is any source of PCDD/Fs emission above the allowed international limits.

Regarding the ndl-PCBs, the highest levels were in the DQ area and had different profile compared to the other samples. The average of levels was $4.72 \mathrm{ng} \mathrm{g}^{-1} \mathrm{~d} . \mathrm{m} .( \pm 2.39)$. The more chlorinated congeners as PCBs 153, 138 and 180 , contributed with $72 \%$ into the sum of MO-PCBs and ndl-PCBs (Figure S1, Supplementary Information section). Frame et al $^{29}$ presented a detailed PCBs congener distribution in Aroclor mixtures. High chlorinated PCBs, such as PCBs 153, 138 and 180 were obtained mostly for Aroclors 1260 and 1262 . These data had similar profile to that obtained in the DQ samples.

Of the 209 different congeners of PCBs, about 140 to 150 are observed in the commercial mixtures produced for electrical equipment. One of the most known technical mixture bears the brand name Aroclor (Trade Name Aroclor in USA, formerly manufactured by Monsanto, Corp., St. Louis, MO, USA), but have never been produced in Brazil, meaning that all PCB mixtures used in Brazil were imported from USA. ${ }^{12,30}$ 


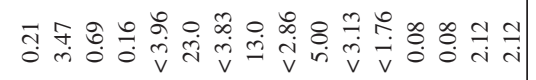
等

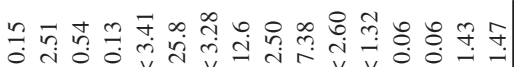

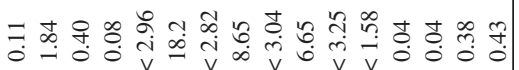

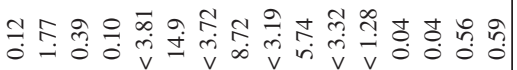

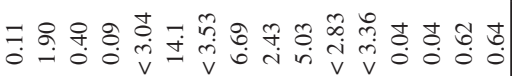
Oे

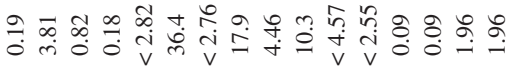

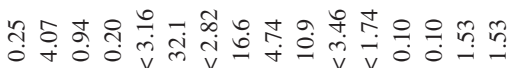

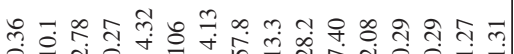

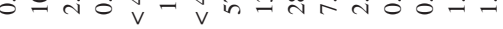

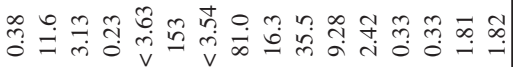

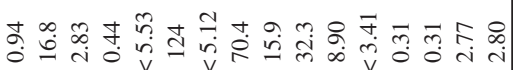

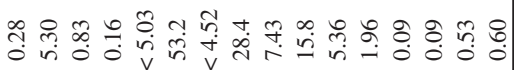

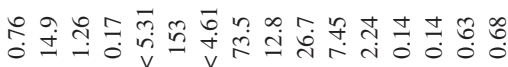

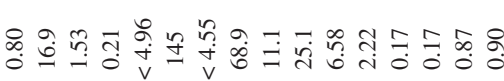

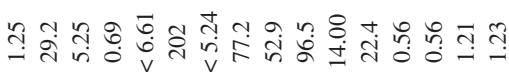

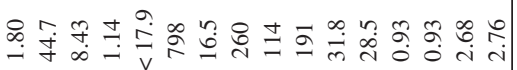

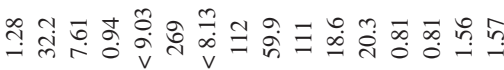

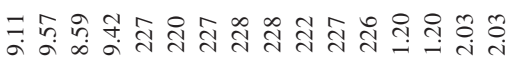
O̊.

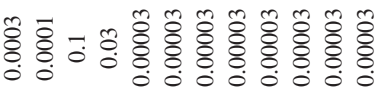

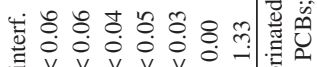

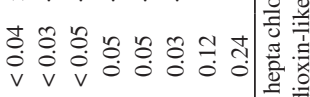

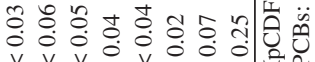

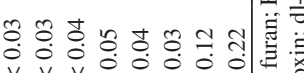

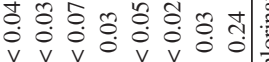

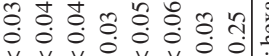

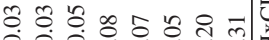
$v$ v

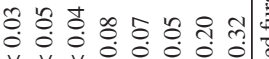
(1)

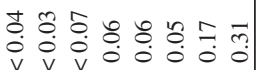

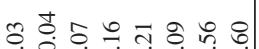

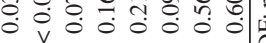

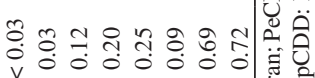

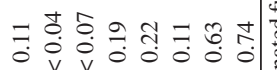

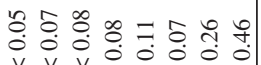

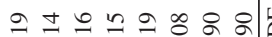
000000000 $\pm= \pm \pm \infty$ 0.00000000 ○ ० $m \vec{m} ㅇ ㅛ$

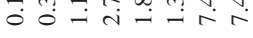

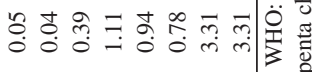

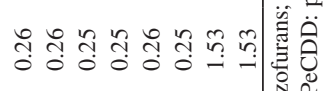

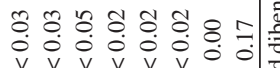




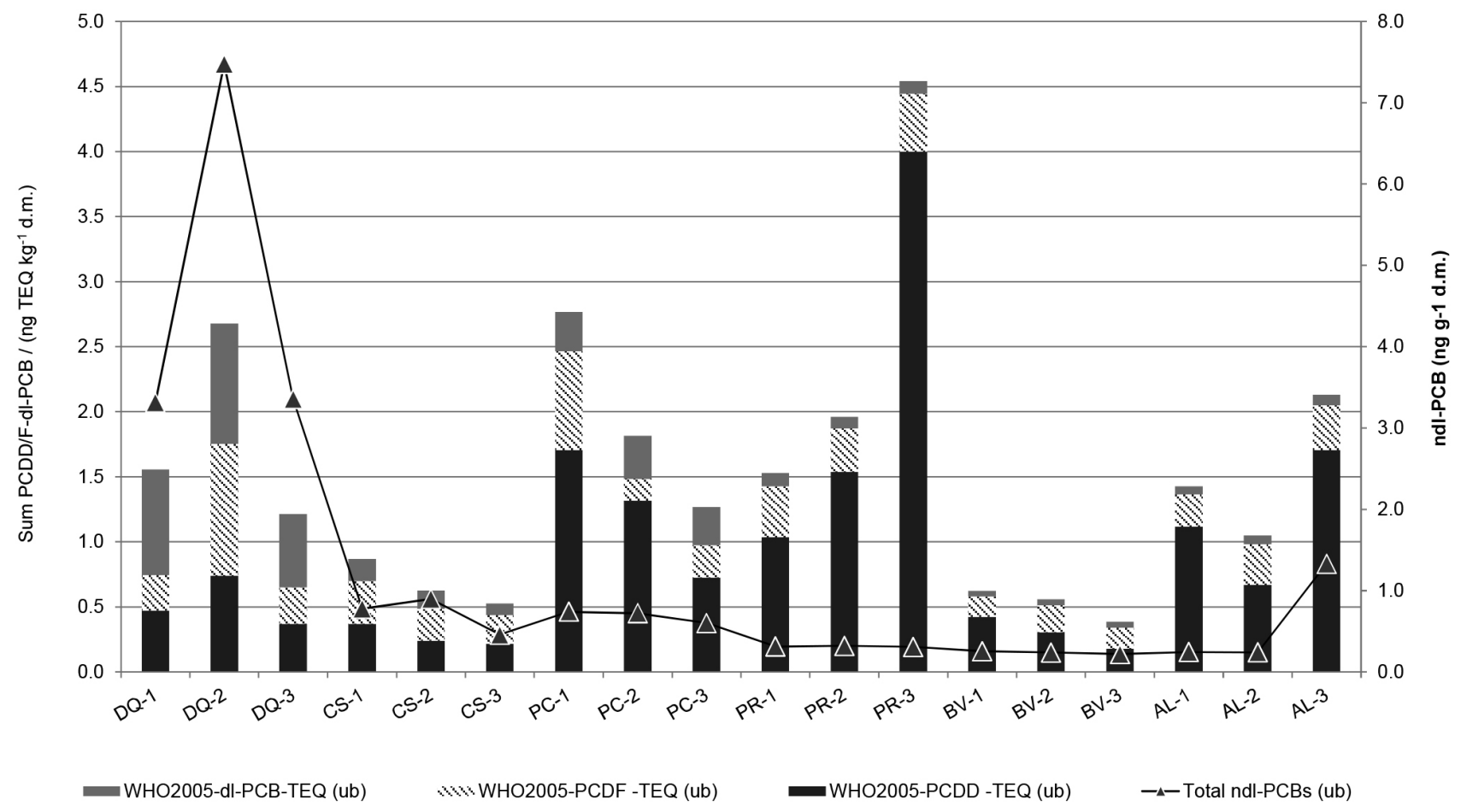

Figure 2. TEQ levels in individual soils of PCDD/Fs and dl-PCBs, and levels of ndl-PCBs.

To evaluate a possible contamination source in the DQ site, the patterns of MO-PCBs and ndl-PCBs found in the three collecting samples (DQ-1, DQ-2 and DQ-3), were compared with the individual patterns previously obtained for each mixture of Aroclor (1016, 1221, 1232, 1242, 1248, 1254,1260 and 1262). Additionally, the Pearson coefficient correlation ( $\rho$ ) between Aroclors and DQ samples was calculated. The mostly positive correlation $(\rho)$ with soil from DQ was Aroclor $1260(\rho=0.91)$, followed by 1262 $(\rho=0.78)$, and $1254(\rho=0.44)$. Figure 3 represents graphically a comparison of the DQ average results and the sum of Aroclors 1254, 1260 and 1262, multiplied by a factor of 65 to be comparable. These positive correlations suggest that PCBs found in the DQ area may be affected mainly by Aroclor mixtures 1254, 1260 and 1262. The reason for such contamination can be near the area collected. As mentioned before, Aroclor mixtures were used as dielectric fluids in electronic components such as capacitors and transformers. ${ }^{11}$ The sampling area DQ was located approximately 70 meters away from the Extra High Voltage Laboratory. This laboratory works with transformers and some were placed outside of the building, near the entrance of the Department of Chemistry. It is very likely that in those transformers Aroclor mixtures were used as dielectric fluids. Consequently residues of PCBs spread across the area contaminating all the locations around. More studies are needed to evaluate the scope of these PCBs residues and risks to the human health.
Comparison with other studies and guidelines for soils

Similar results for the TEQ-PCDD/Fs-dl-PCBs were reported for soils sampled in vicinity of potential industrial sources (ferrous metal producer), in South Africa (ranged 0.12-16 ng TEQ $\mathrm{kg}^{-1}$ d.m.). The authors observed that most levels were below $6.3 \mathrm{ng}$ TEQ $\mathrm{kg}^{-1} \mathrm{~d}$.m. and only one area exceeded this value. ${ }^{27} \mathrm{In}$ an eastern district of China the background of PCDD/Fs and dl-PCBs in soils was investigated, where levels of 0.017-5.04 ng TEQ kg-1 d.m. with mean value of $0.967( \pm 1.361)$, were observed. ${ }^{31}$ In 2012 reported levels of PCDD/Fs and PCBs in soils collected near to potential emission sources from Slovakia were 0.30-15 ng TEQ $\mathrm{kg}^{-1}$ d.m. (i.e., incinerators and metallurgical process). ${ }^{32}$ The European Commission DG Environment produced in 1999 a compilation of dioxin exposure and health data from EU member states. Table S5 (Supplementary information section) displays the levels of PCDD/Fs and PCBs verified in some countries from Europe, Asia, Africa and Americas, in different types of

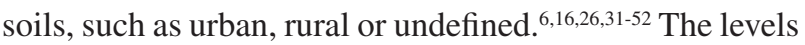
from Belo Horizonte samples are mostly lowers than the levels from the EU member states. The Netherlands reported levels among 2.2-10 ng TEQ $\mathrm{kg}^{-1} \mathrm{~d}$.m. and Spain 0.1-8.4 ng TEQ $\mathrm{kg}^{-1} \mathrm{~d}$.m. for rural soil. Levels in Germany and United Kingdom were 0.1-42 and 0.78-87 ng TEQ $\mathrm{kg}^{-1}$ d.m., respectively, for different types of soils. Quality guidelines of Germany, ${ }^{6}$ Canada $^{49}$ and 


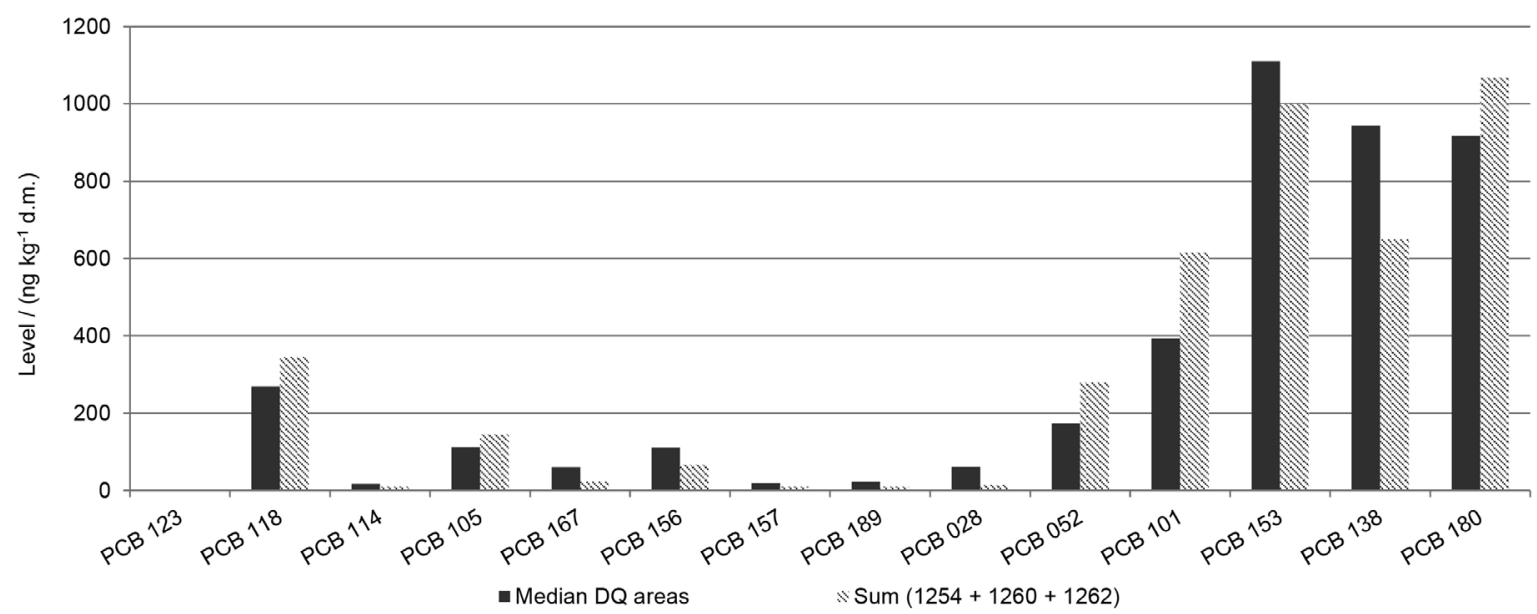

Figure 3. Levels of MO-PCBs and ndl-PCBs ( $\mathrm{n} \mathrm{kg}^{-1}$ d.m.) obtained from soil sampled in Belo Horizonte and the profile for the Aroclor mixture reported by RIKILT.

$\mathrm{USA}^{51}$ were used to compare with levels found in the present study. Sample PR-3 (level found $4.54 \mathrm{ng}$ TEQ $\mathrm{kg}^{-1}$ d.m.), was the only one out of place sample exceeding the restrict guideline by the Canadian Council Ministers of the Environment for agricultural, residential/parkland, and commercial land uses (4 ng TEQ kg-1 d.m.), while German and USA guidelines range from 5 to $10 \mathrm{ng}$ TEQ $\mathrm{kg}^{-1} \mathrm{~d} . \mathrm{m} .{ }^{49}$

\section{Results of dioxins in Brazil}

One of the main studies involving environmental levels and related to human health in Brazil was reported by United Nations Environment. ${ }^{16}$ The published data on concentrations of PCDD/Fs in soils of some locations in Brazil are presented in Table S6 (Supplementary Information section). In this report, levels of some cities like Araraquara-SP, Cantagalo-RJ, Manaus-AM and a recreational area in Rio de Janeiro (0.1-1.2, 0.6-2.5, 0.05-0.4 and 0.03-1.8 ng I-TEQ $\mathrm{kg}^{-1}$ d.m., respectively) are comparable to the amount obtained in soils of Belo Horizonte-MG (0.38-4.44 ng TEQ kg ${ }^{-1}$ d.m). However, the levels in Belo Horizonte are lower than those found in soils from the cities of Cubatão-SP, Formiga-MG and Duque de Caxias-RJ (11-341, 1.4-654 and 13-900 ng I-TEQ kg ${ }^{-1}$ d.m., respectively) and in unspecified industrial areas in Rio de Janeiro (1.1-654 ng I-TEQ $\mathrm{kg}^{-1}$ d.m.). ${ }^{16}$ The highest register were found by Braga et al. ${ }^{15}$ in the region known as Cidade dos Meninos, at the municipality of Duque de Caxias-RJ, where a pesticide facility was located, which currently is not operational. Soil samples contained PCDD/F levels of $13900 \mathrm{ng} \mathrm{I}^{-T E Q ~ ~ k^{-1}}( \pm 0.9 \%)$ whereas samples from the neighborhood ranged from 0.19 to

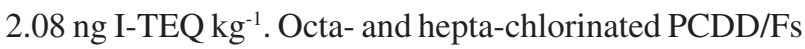
were the main homologues found in the area affected by the pesticides. ${ }^{15}$

\section{Conclusions}

The levels of PCDD/Fs and dl-PCBs in soils from Belo Horizonte-MG ranged from 0.43 to $4.54 \mathrm{ng}$ TEQ $\mathrm{kg}^{-1} \mathrm{~d}$.m. This range is comparable to those found in other Brazilian cities like Manaus-AM, Araraquara-SP and Rio de JaneiroRJ, but smaller than PCDD/Fs levels in Cubatão-SP, Formiga-MG or Duque de Caxias-RJ. Although Belo Horizonte-MG is a metropolitan city with high population density and intense industrial activity, the levels found in six locations studied are lower than those observed in other densely populated areas in the world. Such levels could not be associated with any likely source of contamination located on the outskirts of Belo Horizonte. For a more detailed assessment of these possible sources of emissions, further studies are needed covering the whole metropolitan area, especially in the more industrialized areas like the industrial district of Contagem.

Concentrations of ndl-PCBs obtained for soil in the DQ area were higher than other locations in Belo Horizonte. Comparing data of PCBs congener and Aroclor mixture, positive correlations were observed for Aroclor mixtures 1260, 1262 and 1254. A possible source of this contamination may be associated with some transformers placed around.

The results reported in this paper can be used to help to evaluate the extent of PCDD/Fs and PCBs contamination, and contribute to the knowledge on background of dioxin and PCB concentrations in soils from urban areas in Brazil.

\section{Supplementary Information}

Supplementary information (Figure S1, Table S1-S6) is available free of charge at http://jbcs.sbq.org.br as PDF file. 


\section{Acknowledgments}

The authors are grateful to RIKILT Institute of Food Safety for all the technical support as well as Conselho Nacional de Desenvolvimento Científico e Tecnológico (CNPq), Coordenação de Aperfeiçoamento de Pessoal de Nível Superior (CAPES) and Fundação de Amparo à Pesquisa de Minas Gerais (FAPEMIG) for the financial assistance and fellowships.

\section{References}

1. World Health Organization (WHO); Dioxins and Their Effects on Human Health; Geneva, Switzerland, 2014, fact sheet No. 225.

2. http://chm.pops.int/TheConvention/ThePOPs/ListingofPOPs/ tabid/2509/Default.aspx, Stockoholm Convention on POPs, accessed in August 2016.

3. Van den Berg, M.; Birnbaum, L. S.; Denison, M.; de Vito, M.; Farland, W.; Feeley, M.; Fiedler, H.; Hakansson, H.; Hanberg, A.; Haws, L.; Rose, M.; Safe, S.; Schrenk, D.; Tohyama, C.; Tritscher, A.; Tuomisto, J.; Tysklind, M.; Walker, N.; Peterson, R. E.; Toxicol. Sci. 2006, 93, 223.

4. Van den Berg, M.; Bosveld, A. T.; Brunstrom, B.; Cook, P.; Feeley, M.; Giesy, J. P.; Hanberg, A.; Hasegawa, R.; Kennedy, S. W.; Kubiak, T.; Larsen, J. C.; van Leeuwen, F. X.; Liem, A. K.; Nolt, C.; Peterson, R. E.; Poellinger, L.; Safe, S.; Schrenk, D.; Tillitt, D.; Tysklind, M.; Younes, M.; Waern, F.; Zacharewski, T.; Environ. Health Perspect. 1998, 106, 775.

5. Giesy, J. P.; Kannan, K.; Crit. Rev. Toxicol. 1998, 28, 511.

6. Buckley-Golder, D. P. C.; Davies, M.; King, K.; Petersen, A.; Watterson, J.; Woodfield, M.; Fiedler, H.; Hanberg, A.; Compilation of EU Dioxin Exposure and Health Data; Report No. AEAT/EEQC/0016; European Commission, DG Environment, 1999.

7. Brzuzy, L. P.; Hites, R. A.; Environ. Sci. Technol. 1996, 30, 797.

8. Fiedler, H.; Chemosphere 1996, 32, 55.

9. Tuppurainen, K.; Asikainen, A.; Ruokojärvi, P.; Ruuskanen, J.; Acc. Chem. Res. 2003, 36, 652.

10. Wagrowski, D. M.; Hites, R. A.; Environ. Sci. Technol. 2000, 34, 2952.

11. Rushneck, D. R.; Beliveau, A.; Fowler, B.; Hamilton, C.; Hoover, D.; Kaye, K.; Berg, M.; Smith, T.; Telliard, W. A.; Roman, H.; Ruder, E.; Ryan, L.; Chemosphere 2004, 54, 79.

12. United Nations Environment Programme (UNEP); Guidelines for the Identification of PCBs and Materials Containing PCBs; UNEP Chemicals: Châtelaine, Switzerland, 1999.

13. Wania, F.; MacKay, D.; Environ. Sci. Technol. 1996, 30, 390A.

14. Fiedler, H. In Persistent Organic Pollutants; Fiedler, H., ed.; Springer: Châtelaine, Switzerland, 2003, ch. 6.
15. Braga, A. M. C. B.; Krauss, T.; Santos, C. R.; Souza, P. M.; Chemosphere 2002, 46, 1329.

16. United Nations Environment Programme (UNEP); The Management of Polychlorinated Biphenyls (PCBs) and Dioxins/ Furans; Montevideo, Uruguay, 2002.

17. http://www.ibge.gov.br/home/estatistica/populacao/ estimativa2014/, accessed in August 2016.

18. Silva, A. B. O.; Alves, J. D.; Nova Econ. 2010, 20, 219.

19. http://www.rmbh.org.br/pt-br/mapa-colaborativo, accessed in August 2016.

20. Tuinstra, L. G. M. T.; Traag, W. A.; van Rhijn, J. A.; van de Spreng, P. F.; Chemosphere 1994, 29, 1859.

21. Leeuwen, S. P. J.; Leonards, P. E. G.; Traag, W. A.; Hoogenboom, L. A. P.; Boer, J.; Anal. Bioanal. Chem. 2007, 389, 321.

22. http://www.wageningenur.nl/nl/Expertises-Dienstverlening/ Onderzoeksinstituten/rikilt/Onderzoek/Stoffen-meten-enopsporen/Contaminanten/Dioxine-analyses/Technique-dioxinanalysis.htm, accessed in August 2016.

23. EN 16215:2012: Animal Feeding Stuffs Determination of Dioxins and Dioxin-Like PCBs by GC/HRMS and of Indicator PCBs by GC/HRMS; European Committee for Standardization, April 2012.

24. Commission Regulation (EU); No. 252/2012 Laying Down Methods of Sampling and Analysis for the Official Control of Levels of Dioxins, Dioxinlike PCBs and Non-Dioxin-Like PCBs in Certain Foodstuffs and Repealing Regulation (EC) No. 1883/2006; Official Journal of the European Union: Brussels, 21 March 2012.

25. Hites, R. A.; Acc. Chem. Res. 1990, 23, 194.

26. Nieuwoudt, C.; Quinn, L. P.; Pieters, R.; Jordaan, I.; Visser, M.; Kylin, H.; Borgen, A. R.; Giesy, J. P.; Bouwman, H.; Chemosphere 2009, 76, 774.

27. Domingo, J. L.; Granero, S.; Schuhmacher, M.; Chemosphere 2001, 43, 517.

28. Ames, M.; Zemba, S.; Green, L.; Botelho, M. J.; Gossman, D.; Linkov, I.; Palma-Oliveira, J.; Sci. Total Environ. 2012, 419, 37.

29. Frame, G. M.; Cochran, J. W.; Bøwadt, S. S.; J. High Resolut. Chromatogr. 1996, 19, 657.

30. United Nations Environment Programme (UNEP); $P C B$ Transformers and Capacitors from Management to Reclassification and Disposal; UNEP Chemicals, 2002.

31. Liu, J.; Liu, W.; J. Hazard. Mater. 2009, 163, 959.

32. Dömötörová, M.; Sejáková, Z. S.; Kočan, A.; Čonka, K.; Chovancová, J.; Fabišiková, A.; Chemosphere 2012, 89, 480.

33. Rogowski, D. L.; Yake, W.; Environ. Sci. Technol. 2005, 39 , 5170 .

34. Mamontov, A. A.; Mamontova, E. A.; Tarasova, E. N.; McLachlan, M. S.; Environ. Sci. Technol. 2000, 34, 741.

35. Eljarrat, E.; Caixach, J.; Rivera, J.; Environ. Sci. Technol. 1997, $31,2765$. 
36. Fiedler, H.; Rappolder, M.; Knetsch, G.; Basler, A.; Organohalogen Compd. 2002, 57, 37.

37. Buckland, S. J.; Ellis, K. H.; Salter, R. T.; Scobier, S. E.; Organohalogen. Comp. 1998, 39, 101.

38. Nakao, T.; Ohta, S.; Aozasa, O.; Miyata, H.; Organohalogen Comp. 1999, 43, 221.

39. Im, S. H.; Kannan, K.; Giesy, J. P.; Matsuda, M.; Wakimoto, T.; Environ. Sci. Technol. 2002, 36, 3700.

40. Fré, R. D.; Wevers, M.; Organohalogen Comp. 1998, 38, 113.

41. Assmuth, T. W.; Vartiainen, T.; Chemosphere 1995, 31, 2853.

42. Martens, D.; Balta-Brouma, K.; Brotsack, R.; Michalke, B.; Schramel, P.; Klimm, C.; Henkelmann, B.; Oxynos, K.; Schramm, K. W.; Diamadopoulos, E.; Kettrup, A.; Chemosphere 1998, 36, 2855.

43. Berlincioni, M. G. C.; Ferri, F.; Iacovella, N.; La Rocca, C.; Lolini, M.; Megli, A.; Pupp, M.; Rizzi, L.; Turrio-Baldassari, L.; di Domenico, A.; Fresenius Environ. Bull. 1995, 4, 169.

44. Domingo, J. L.; Schuhmacher, M.; Granero, S.; de Kok, H. A. M.; Environ. Monit. Assess. 2001, 69, 175.

45. Matthijsen, A. J. C. M.; Van den Berg, R.; Derks, H. J. G. M.; Van Jaarsveld, J. A.; de Jong, A. P. J. M.; Slob, W.; Theelen, R. M. C.; Sein, A. A.; Evaluation of the Relations Between Dioxin Emission Measurements of the Municipal Solid Waste Incinerator OLAF-Leeuwarden with Concentrations in Soil and Milk in the Vicinity of the Incinerator, Report No. 730501027,
National Institute for Public Health and the Environment: Bilthoven, Netherlands, 1991.

46. Schuhmacher, M.; Granero, S.; Llobet, J. M.; de Kok, H. A.; Domingo, J. L.; Chemosphere 1997, 35, 1947.

47. Creaser, C. S.; Fernandes, A. R.; Al-Haddad, A.; Harrad, S. J.; Homer, R. B.; Skett, P. W.; Cox, E. A.; Chemosphere 1989, 18, 767.

48. Takazawa, Y.; Verdugo, R.; Richter, P.; Kitamura, K.; Choi, J. W.; Hashimoto, S.; Ito, H.; Shibata, Y.; Morita, M.; Bull. Environ. Contam. Toxicol. 2004, 73, 543.

49. Canadian Council of Ministers of the Environment (CCME); Guidelines for the Protection of Environmental and Human Health; CCME: Canada, 2002.

50. Müller, J.; Muller, R.; Goudkamp, K.; Shaw, M.; Mortimer, M.; Haynes, D.; Burniston, D.; Symons, R.; Moore, M.; Dioxins in Soils in Australia, National Dioxins Program Technical Report No. 5, Australian Government Department of the Environmental and Heritage: Canberra, 2004.

51. U.S. Department of Health and Human Services; Toxicological Profile for Chlorinated Dibenzo-p-Dioxins; Atlanta, GA, 1998.

52. Boos, R.; Himsl, A.; Wurst, F.; Prey, T.; Scheidl, K.; Sperka, G.; Gläser, O.; Chemosphere 1992, 25, 283.

Submitted: April 26, 2016

Published online: August 18, 2016 